\title{
Synthesis, characterisation and gas permeation studies on microporous silica and alumina-silica membranes for separation of propane and propylene
}

\author{
Balagopal N. Nair ${ }^{1}$, Klaas Keizer, Wilma J. Elferink, Melis J. Gilde, Henk Verweij, \\ Anthonie J. Burggraaf \\ Inorganic Material Science, Faculty of Chemical Technology, University of Twente, 7500 AE Enschede, The Netherlands
}

Received 21 August 1995; accepted 15 January 1996

\begin{abstract}
Microporous silica membranes are known to exhibit molecular sieving effects. However, separation of nearly equal sized molecules is difficult to carry out by size exclusion. Introducing sorption selectivity and keeping the kinetics favourable to facilitate a good contribution of permeation from sorption is a possible solution to enhance selectivity of adsorbing molecules. Results are presented in this paper on the synthesis of a microporous silica membrane with commendable permselectivity between helium and propylene. Modifications are performed on the membrane to improve its almost non-selective nature to propylene/propane mixtures to give practical separation values. Gas separation results on the modified membranes are presented. Surface selectivity on the newly added alumina surface layer is identified as the helping mechanism in realising this separation.
\end{abstract}

Keywords: Sol-gel process; Silica membrane; Gas separation; Surface selectivity; Microporous

\section{Introduction}

The development of ceramic microporous membranes with good gas separation properties have been described in many recent articles [1-4]. Some of these membranes consisted of a porous support modified with a silica microporous component by either the CVD or sol-gel technique. In the case of sol-gel modification [5-9] polymeric silica molecules are

\footnotetext{
'Present address: Advanced Polymer Laboratory, Japan High Polymer Center, 22-13 Yanagibashi 2-Chome, Taito-ku, Tokyo 111, Japan. Fax: 81-3-3866-8340.
}

deposited on the top of a support system consisting of a microns thick mesoporous $\gamma-\mathrm{Al}_{2} \mathrm{O}_{3}$ over a macroporous $\alpha-\mathrm{Al}_{2} \mathrm{O}_{3}$ of desired thickness. The silica layer is then calcined at $400^{\circ} \mathrm{C}$ to end up as the separating top layer with a thickness of $50-100 \mathrm{~nm}$.

This asymmetric membrane system has shown molecular sieving effects on molecules larger than 5-6 $\AA$ and is found to be good for separating $\mathrm{H}_{2}$ and $\mathrm{He}$ from larger hydrocarbons. It is however difficult to separate molecules of nearly the same molecular size such as paraffin-olefins, $\mathrm{O}_{2}-\mathrm{N}_{2}$, etc. With such combinations the size exclusion effect is difficult in practice and when it comes to dissolution (such as the separation of $\mathrm{O}_{2}$ with a dense perovskite mem- 
brane) the application is limited to specific ions at very high temperature [10].

Introducing sorption selectivity instead of diffusion selectivity as in the case of polymeric membranes may be a solution for such separations. However, ceramic membranes are generally porous and brittle and a swelling type mechanism is impossible in practice except in pillared clay like materials with a comparatively loose structure [11].

For sorption to be the separating mechanism a high sorption capacity (higher concentration and hence higher driving force) is needed and non-selective transport (diffusive, leakage) should be minimised. Direct gas phase entry into the micropore followed by non-selective diffusion can lead to lower separation factors. For high sorption capacity the porosity and the internal surface area of the membrane has to be increased. The problem is then that the pore size will increase to the mesoporous range, increasing non-selective gas phase transport.

Increasing the surface area above the micropore with sorption selective material was hence introduced in this paper. A schematic of the modified membrane system is shown in Fig. 1. The starting point is the existing silica membrane with no or negligible selectivity for the molecular mixtures to be separated. Gas phase transport is minimum ( $D_{\text {pore }}$ $\left.\cong D_{\text {molecule }}\right)$ and hence external steady state sorption is rate determining [12]. This silica membrane is then provided with a porous sorption selective layer with a high sorption capacity. Under steady state conditions this results in a concentration difference of the sorbed components and therefore a driving force difference at the interface between the layers. This

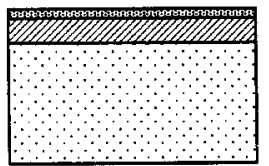

(a)

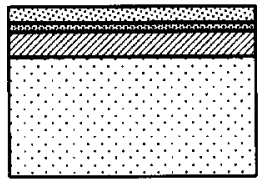

(b)
Alumina sorption selective layer

Silica micro-porous layer

Gamma alumina meso-porous support layer

Alpha alumina macro-porous support

Fig. 1. Schematic of (a) silica membrane $\mathrm{SiO}_{2}$, (b) silica membrane with alumina sorption selective top layer $\mathrm{Al}_{2} \mathrm{O}_{3}-\mathrm{SiO}_{2}$. selectivity at the interface will be rate determining under conditions where molecular exchange at the silica pore mouth directly from the gas phase is minimum. Reasonably high adsorption capacity of the new top-layer is helpful in this regard.

The separation selectivity is now determined by the driving force difference and not by the difference in diffusion through the silica layer. Because of transport, concentration of the highly sorbed species at the interface can decrease faster. Therefore the sorption capacity has to be large and the kinetics faster to realise separation effects under steady state conditions. These limit the possible permeation rates and application of the new membrane system.

In this paper experiments are presented to show that the concept of introduction of sorption selectivity in ceramic microporous membrane is a possible way to improve separation of similarly sized molecules. For the sorption selective layer $\gamma-\mathrm{Al}_{2} \mathrm{O}_{3}$ has been chosen and propylene and propane of kinetic diameter $(4.5 \AA)$ and $(4.3 \AA)$ were selected as the molecules to be separated.

\section{Experimental}

Polymeric sols were prepared by hydrolysis and condensation of tetraethylorthosilicate (TEOS, Merck, p.a. grade) in ethanol with $\mathrm{HNO}_{3}$ as catalyst [13]. A mixture of $\mathrm{HNO}_{3}$ (Merck, p.a. grade) and water was carefully added, using a dropping funnel, to a mixture of ethanol (ethanol absolute, Merck, p.a. grade) and TEOS under vigorous stirring. The reaction mixture was then refluxed for $3 \mathrm{~h}$ at $65 \pm 5^{\circ} \mathrm{C}$ under stirring. The molar ratio of TEOS:water:ethanol: $\mathrm{HNO}_{3}$ used was 1:6.4:3.8:0.085. The silica sol thus made was diluted to a concentration of $0.1 \mathrm{~mol} / 1$ for dipping the support.

$\alpha$-Alumina supports with a $\gamma$-alumina intermediate layer were then dip coated with this sol. This support (alpha), intermediate layer (gamma) system is Knudsen diffusing [6]. The support system has a roughness of $40 \mathrm{~nm}$ and a porosity of $50-60 \%$. Details of the synthesis and characterisation of these are reported elsewhere [6].

This support was dip coated with silica sol. The dipping time was $4 \mathrm{~s}$. Drying was carried out in a climate chamber $\left(40^{\circ} \mathrm{C}, 60 \% \mathrm{RH}\right)$, followed by calci- 
nation at $400^{\circ} \mathrm{C}$ for $3 \mathrm{~h}$ at a heating rate of $25^{\circ} \mathrm{C} / \mathrm{h}$. Silica unsupported membranes for gas adsorption measurements were made by drying the dip solution in a petri dish at room temperature (in a laminar flow cupboard at a wind velocity of $0.45 \mathrm{~m} / \mathrm{s}$ ). Calcination was carried out in the same way as that of the supported membrane.

Boehmite sol was made by hydrolysis of aluminum-tri-sec-butoxide (Merck, p.a. grade). The alkoxide was added dropwise to water maintained at $90^{\circ} \mathrm{C}$ under vigorous stirring. The water alkoxide ratio was maintained at 70:1. After hydrolysis the boehmite/water mixture was boiled for $1 \mathrm{~h}$ to remove excess alcohol. This was peptised with $1 \mathrm{~N}$ $\mathrm{HNO}_{3}$ by refluxing at $80^{\circ} \mathrm{C}$ for $12 \mathrm{~h}$. The resulting sol had a $\mathrm{pH}$ of 4 and a molarity of 1 . This sol was concentrated by evaporation and then re-dispersed in ethanol to a concentration of $0.125 \mathrm{~mol} / 1$. This boehmite dip solution was used for making the alumina sorption selective top-layer for the silica microporous membrane. Dipping, drying and calcining procedures were kept the same as those for the silica microporous layer.

Philips PW 1710 X-ray diffractometer was used to evaluate the phases of the dried and calcined gels. The cross-sectional structure of the supported membranes were observed with a Hitachi S-900 FESEM.

Sorption studies were performed on unsupported membranes (gels) with a Carlo Erba Sorptomatic 1900 apparatus attached to a turbo molecular pump. Nitrogen adsorption studies at liquid nitrogen temperature were used to characterise the pore structure of the material. Propylene and propane adsorption on silica and alumina calcined gels were carried out in the same set up. Isosteric heat of adsorption $\left(q_{\mathrm{st}}\right)$ was calculated from adsorption isotherms of propylene $\left(\mathrm{C}_{3} \mathrm{H}_{6}\right.$, coded $\mathrm{Pl}$ in figures $)$ and propane $\left(\mathrm{C}_{3} \mathrm{H}_{8}\right.$, coded $\mathrm{Pa}$ in figures) at different temperatures using standard expressions [14].

Supported membranes of silica $\left(\mathrm{SiO}_{2}\right.$, coded $\mathrm{Si}$ in figures $)$ and silica with an alumina top-layer $\left(\mathrm{Al}_{2} \mathrm{O}_{3}\right.$ $\mathrm{SiO}_{2}$, coded $\mathrm{Al}-\mathrm{Si}$ in figures) were tested for Helium (He) and $\mathrm{C}_{3} \mathrm{H}_{6}$ single gas permeations in a pressure controlled set up equipped with analog flow read outs and programmed heating. Single gas permeations were carried out by applying constant pressure ( $50 \mathrm{KPa}$ here) on the top layer of the membrane and vacuum on the back side. An extensive description of the equipment and experimental procedures is given by Vroon et al. [15]. The apparent activation energy $\left[E_{\text {act }}\right]$ for permeation was calculated from an Arrhenius plot.

Multi-component separation experiments were done with a Wicke-Kallenbach [16] set up, attached to a gas chromatograph for permeate, feed and retentate analysis. Equimolar mixtures of $\mathrm{C}_{3} \mathrm{H}_{6}$ and $\mathrm{C}_{3} \mathrm{H}_{8}$ were used with an Argon sweep at 1 bar and 15 $\mathrm{ml} / \mathrm{min}$ flow. Separation factors were calculated taking the ratio of permeate to feed concentration of individual components. This generally gives a pessimistic result since the average concentration over the membrane top-layer in a cross flow set up is always less than the feed concentration.

Consistency experiments were performed with silica and alumina sols made from different batches of chemicals and on alumina supports from different batches. Time dependant permeation behaviour was performed on the multicomponent separation set up under the previously described conditions. The membrane was tested till $200^{\circ} \mathrm{C}$ each time even though the results reported were at $50^{\circ} \mathrm{C}$. For pore cleaning the membranes were heat treated $\left(<400^{\circ} \mathrm{C}\right)$ after removal from the set up under ordinary furnace conditions. Propylene permeation was calculated from the multiple gas mixture from the area of the integrated chromatographic peak. Aging experiments were performed by exposing the membrane to ambient atmosphere, followed by re-testing the permeation behaviour of the membrane.

\section{Results}

A nitrogen adsorption isotherm of the calcined silica unsupported membrane (gel) is shown in Fig. 2. The type 1 isotherm establishes the microporous nature of the material. The micropore volume was calculated as $20 \%$ from the adsorbed nitrogen volume by the isotherm intercept method [8]. H-K analysis was performed on the isotherm points to give a mean pore size of $5.5 \AA$. Details of this analysis can be found elsewhere [8b].

Propylene adsorption isotherms over silica gel at different temperatures are shown in Fig. 3. At low temperatures sorption is of the Langmuir type. The 


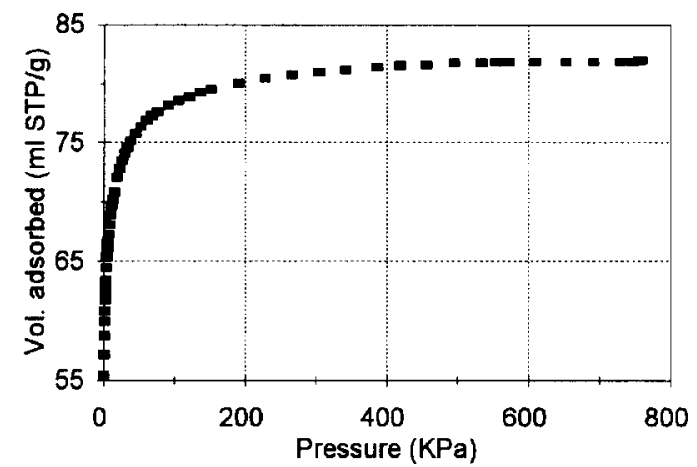

Fig. 2. Nitrogen adsorption isotherm of calcined silica unsupported membrane.

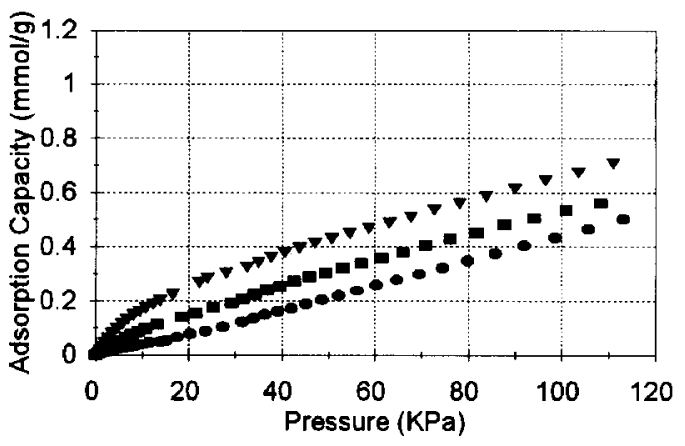

$-298 \mathrm{~K} \cdot 373 \mathrm{~K}=323 \mathrm{~K}$

Fig. 3. Propylene adsorption isotherms of calcined silica unsupported membrane.

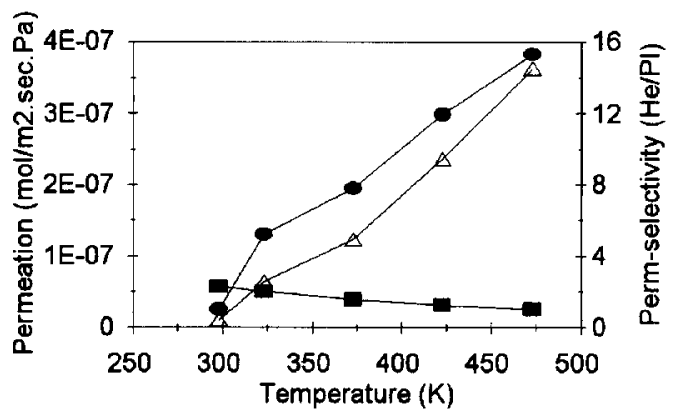

$$
\begin{aligned}
& \text { - Helium } \\
& \triangle \text { He/PI Perm-selectivity }
\end{aligned}
$$

Fig. 4. Single gas permeation through silica $\left(\mathrm{SiO}_{2}\right)$ membrane at $50 \mathrm{KPa}$. isosteric heat of adsorption of propylene over silica was calculated from these data. At low coverage ( 0.1 $\mathrm{mmol} / \mathrm{g}$ ) silica gel showed a very high isosteric heat of adsorption of $19.7 \mathrm{~kJ} / \mathrm{mol}$. However $q_{\mathrm{st}}$ values went down to $11.9 \mathrm{~kJ} / \mathrm{mol}$ as the coverage increased to $0.5 \mathrm{mmol} / \mathrm{g}$.

Helium permeation results through the silica supported membrane are shown in Fig. 4. Diffusion was activated with an apparent activation energy of $9.3 \pm$ $0.4 \mathrm{~kJ} / \mathrm{mol}$ (not corrected for support resistance). Propylene permeation shown in Fig. 4 is reasonably good. However the permeation in this case was sorption controlled giving a decrease with increasing temperature. Hence the permselectivity of helium $(2.6 \AA)$ to propylene $(4.5 \AA)$ showed a maximum value of 14.5 at the highest measured temperature $\left(200^{\circ} \mathrm{C}\right)$ as shown in Fig. 4.

However multicomponent separation results with propylene/propane mixtures showed only very small selectivity. Separation factors $\left(\mathrm{RT}-200^{\circ} \mathrm{C}\right)$ always remained in the vicinity of 1 .

Such silica membranes were dip coated with alumina sols (see Fig. 1) to make $\mathrm{Al}_{2} \mathrm{O}_{3}-\mathrm{SiO}_{2}$ membranes. The alumina coating (gel) was mesoporous. The type $4 \mathrm{~N}_{2}$ adsorption isotherm of the gel showed a total porosity of about $50 \%$ and a BET pore size of $36 \AA$. X-ray diffraction analysis revealed the structure of the starting material (sol) as boehmite and calcined gel as gamma alumina. Propylene adsorption results on alumina showed Langmuir adsorption behaviour as in Fig. 5a. $\mathrm{C}_{3} \mathrm{H}_{6}$ showed a small decrease in $q_{\mathrm{st}}$ with coverage from 18.8 to 15.7 $\mathrm{kJ} / \mathrm{mol}$ as the concentration increased from 0.1 to $0.5 \mathrm{mmol} / \mathrm{g}$. Propane adsorption isotherms of alumina are shown in Fig. 5b. The sorption was of the Langmuir type with an insignificant increase of $q_{\mathrm{st}}$ from 15 to $16.6 \mathrm{~kJ} / \mathrm{mol}$ while the coverage increased from 0.1 to $0.3 \mathrm{mmol} / \mathrm{gm}$. The isotherms identify a selectivity for propylene over propane on alumina. The ratios of adsorption capacity and the Henry slope [14] of these molecules are in the range $1.5-2$ throughout the temperature range of investigation.

FESEM observations confirmed the sandwich structure of the $\mathrm{Al}_{2} \mathrm{O}_{3}-\mathrm{SiO}_{2}$ membrane (Figs. 6a and $6 \mathrm{~b})$. The silica active layer between the two alumina layers was only $40 \mathrm{~nm}$ thick (Fig. 6b), between the arrows). The total thickness of the three sol-gel 

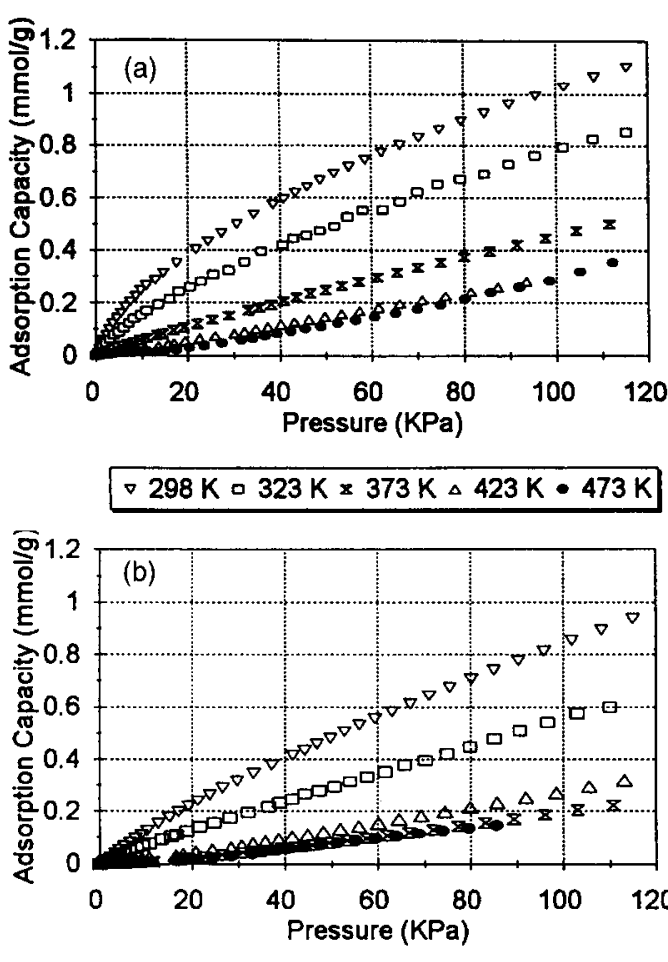

$\nabla 298 K \square 323 K \triangle 373 K \times 423 K \cdot 473 K$

Fig. 5. (a) Propylene adsorption isotherms of calcined alumina unsupported membrane. (b) Propane adsorption isotherms of calcined alumina unsupported membrane.

layers together was about $3800 \mathrm{~nm}$ (Fig. 6a). The top alumina layer was about $400 \mathrm{~nm}$ thick.

The alumina-silica $\left(\mathrm{Al}_{2} \mathrm{O}_{3}-\mathrm{SiO}_{2}\right)$ membrane showed microporous diffusion as in the case of silica. Helium permeation results through the membrane is shown in Fig. 7. An apparent activation energy of $10.2 \pm 0.7 \mathrm{~kJ} / \mathrm{mol}$ was calculated. However the propylene permeation results shown in Fig. 7 gave a significantly different view. Propylene permeation through the $\mathrm{Al}_{2} \mathrm{O}_{3}-\mathrm{SiO}_{2}$ membrane is almost an order of magnitude larger than that through $\mathrm{SiO}_{2}$ membrane. As a result the permselectivity of helium to propylene dropped to 2.2 at $200^{\circ} \mathrm{C}$ as shown in Fig. 7.

Multicomponent separation measurements were performed on $\mathrm{C}_{3} \mathrm{H}_{6} / \mathrm{C}_{3} \mathrm{H}_{8}$ mixtures through this membrane. The results are shown in Fig. 8 (see also the separation factor of silica membrane for comparison). The $\mathrm{Al}_{2} \mathrm{O}_{3}-\mathrm{SiO}_{2}$ membrane showed reasonably
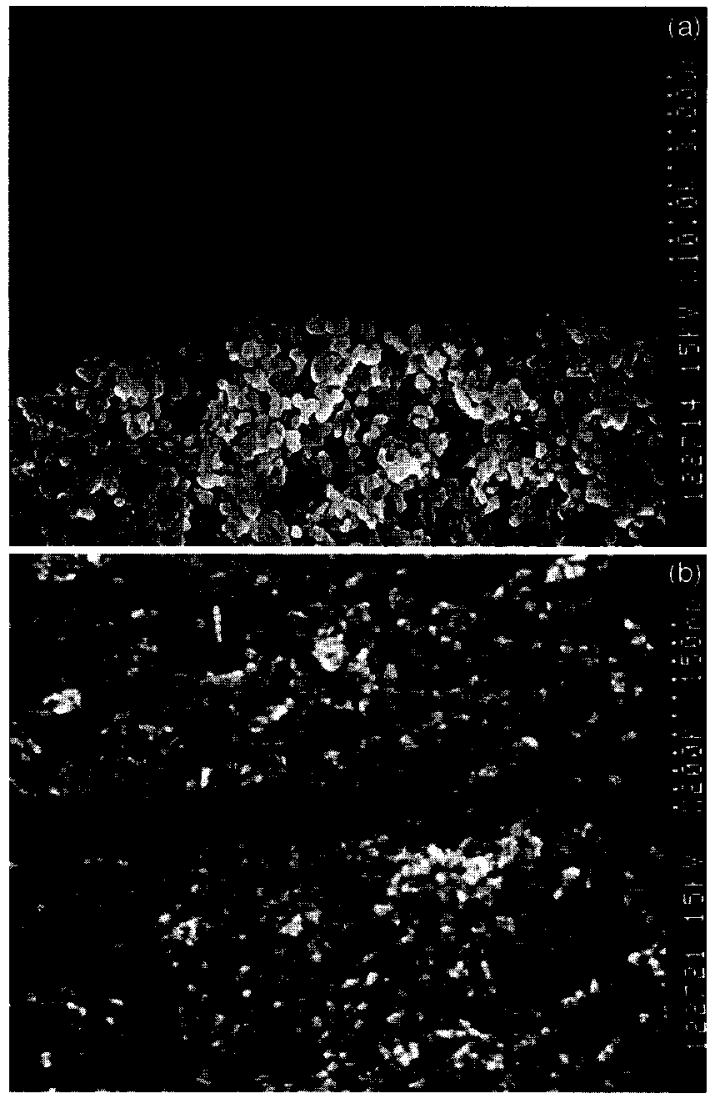

Fig. 6. (a) Cross-sectional FESEM of $\mathrm{Al}_{2} \mathrm{O}_{3}-\mathrm{SiO}_{2}$ membrane showing the support and the sol-gel layer. (b) Cross-sectional view of the sol-gel $\left(\mathrm{Al}_{2} \mathrm{O}_{3}-\mathrm{SiO}_{2}\right.$ membrane) layer showing the silica (between arrows) between the two alumina layers.

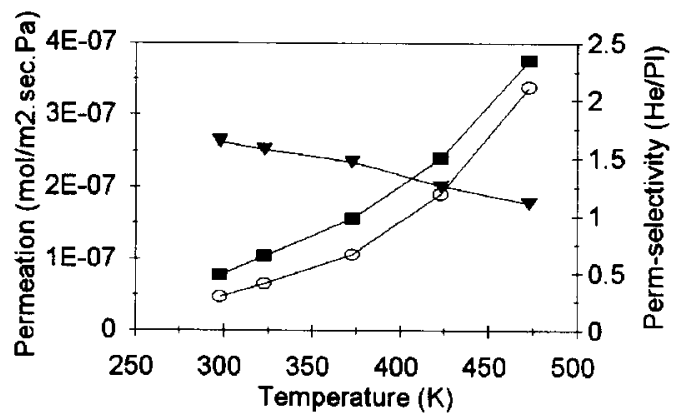

$$
\begin{aligned}
& - \text { Helium } \\
& \Theta \text { Perm-selectivity (He/PI) }
\end{aligned}
$$

Fig. 7. Single gas permeation through silica membrane with an alumina top layer $\left(\mathrm{Al}_{2} \mathrm{O}_{3}-\mathrm{SiO}_{2}\right)$ at $50 \mathrm{KPa}$ 


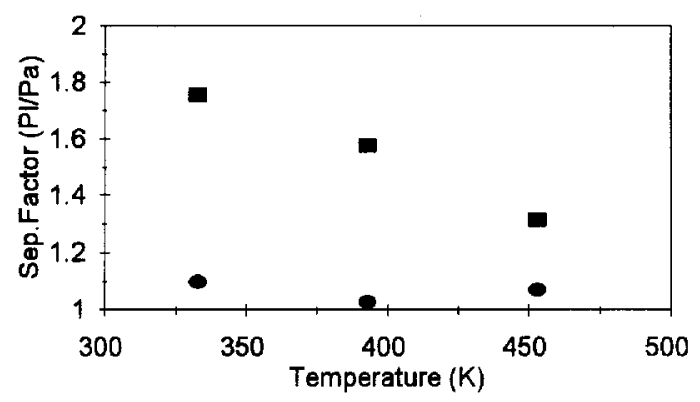

- Al-Si Membrane - Si Membrane

Fig. 8. Multicomponent separation of $\mathrm{C}_{3} \mathrm{H}_{6} / \mathrm{C}_{3} \mathrm{H}_{8}$ mixture through $\mathrm{SiO}_{2}$ and $\mathrm{Al}_{2} \mathrm{O}_{3}-\mathrm{SiO}_{2}$ membranes.

good separation of these gases giving a separation factor of 1.7 at $50^{\circ} \mathrm{C}$. The room temperature separation factor is not reported because of the uncertainty in measurement owing to pore blockage.

\subsection{Consistency and durability measurements}

Gas permeation through $\mathrm{Al}_{2} \mathrm{O}_{3}-\mathrm{SiO}_{2}$ membranes was found to depend largely on synthesis conditions and support quality. Initial permeability of these membranes scattered between $10-40 \mathrm{~m}^{3} / \mathrm{m}^{2}$ bar day. However for membranes with comparable helium $E_{\text {act }}(\sim 10 \mathrm{~kJ} / \mathrm{mol}), \mathrm{C}_{3} \mathrm{H}_{6} / \mathrm{C}_{3} \mathrm{H}_{8}$ separation factors always stayed in the $\pm 5 \%$ range.

Fig. 9 shows the behaviour of $\mathrm{Al}_{2} \mathrm{O}_{3}-\mathrm{SiO}_{2}$ mem-

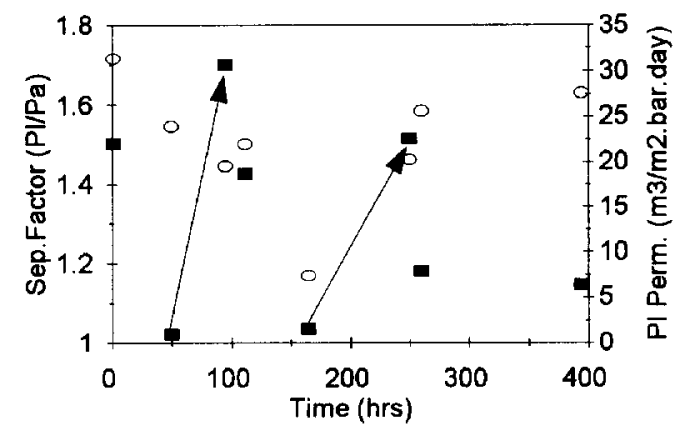

o Separation Factor (PI/Pa) 1 Propylene Permeation

Fig. 9. Change in $\mathrm{C}_{3} \mathrm{H}_{6} / \mathrm{C}_{3} \mathrm{H}_{8}$ separation factor and $\mathrm{C}_{3} \mathrm{H}_{6}$ permeation of an $\mathrm{Al}_{2} \mathrm{O}_{3}-\mathrm{SiO}_{2}$ membrane due to pore clogging and further cleaning (arrows indicate cleaning by heat treatment in between measurements). brane under the test conditions. The separation factor $\left(\mathrm{C}_{3} \mathrm{H}_{6} / \mathrm{C}_{3} \mathrm{H}_{8}\right)$ and propylene permeation (from the mixture) at $50^{\circ} \mathrm{C}$ under the reported test conditions is shown for 8 consecutive tests performed within 17 days of the initial run. The decrease in permeation is associated with pore closure during testing and the increase is made by heat treating the membrane at temperatures ranging from $200-400^{\circ} \mathrm{C}$ under ordinary furnace conditions. The fluctuations in separation factor resulting from this pore clogging and further cleaning is not that severe, however there is no systematic correlation between separation factor and permeation.

Experiments showed that exposure of the membranes $\left(\mathrm{Al}_{2} \mathrm{O}_{3}-\mathrm{SiO}_{2}\right.$ and $\left.\mathrm{SiO}_{2}\right)$ to humid atmospheres can lead to densification. 45 days aging at ambient atmospheres made both the membranes densify permanently. Single gas permeation measurements conducted after aging revealed only a negligibly small contribution from the diffusive flux.

\section{Discussion}

Silica gels can be prepared with microporosity ranging from 0 to $40 \%$ by varying the synthesis conditions and amount of reactants [13]. The present synthesis conditions are moderate leading to nearly linear fractal polymers at the end of the $3 \mathrm{~h}$ synthesis time. The fractal dimension of the polymer was nearly 0.96 and the radius of gyration $17 \AA$ as reported elsewhere [17]. Controlled drying of this sol lead to gels with a microporosity of $20 \%$ as is shown in the nitrogen adsorption isotherm in Fig. 2. The analysis of such isotherms with modified $\mathrm{H}-\mathrm{K}$ type models can give an approximate idea of the pore size and its distribution [8b]. The mean pore size of this membrane was calculated as $5.5 \AA$, which is good enough to show molecular size exclusion effects. However the pore sizes in supported membranes can differ from that of unsupported membranes because of support constraints and differences in drying rates.

Helium permeation results on supported membranes in Fig. 4 supports the microporous structure as shown by the gels. The activation energy measured is comparable to other published results [8a].

This microporous silica gel showed a Langmuir type adsorption of propylene at low temperatures. 
However as the temperature is increased the membrane started showing a Henry type adsorption behaviour (Fig. 3). The isosteric heat of adsorption showed a reduction with increasing concentration. This fall in $q_{\mathrm{st}}$ can be associated with an energetically heterogeneous silica surface [18]. The preferential sorption in the micropores should be the reason for this heterogeneity [19]. This guarantees a strong concentration of $\mathrm{C}_{3} \mathrm{H}_{6}$ in the micropores of silica. The strongly sorption controlled permeation of $\mathrm{C}_{3} \mathrm{H}_{6}$ through the $\mathrm{SiO}_{2}$ membrane during the single gas permeation measurement was hence expected. The permeation of propylene through the membrane showed a decreasing trend with increasing temperature (Fig. 4). As can be realised from the individual permeation values of helium and propylene through the membrane, the permselectivity between the gases was reasonably high.

$\mathrm{C}_{3} \mathrm{H}_{6} / \mathrm{C}_{3} \mathrm{H}_{8}$ separation results were not encouraging. It was seen that $\mathrm{C}_{3} \mathrm{H}_{6}$ permeation through the membrane is sorption controlled. So the absence of separation between the gases points to an absence in steady state sorption selectivity between the gas molecules on silica surface and pore mouth [20]. To realise this separation a membrane with high adsorption capacity and surface selectivity of the target molecule has to be designed. However the thin structure and small pore sizes always keeps the adsorption capacity of the separating layer small.

Efforts to make $\mathrm{C}_{3} \mathrm{H}_{6} / \mathrm{C}_{3} \mathrm{H}_{8}$ selective microporous membranes out of alumina, which showed reasonably high equilibrium adsorption capacity and selectivity over $\mathrm{C}_{3} \mathrm{H}_{6} / \mathrm{C}_{3} \mathrm{H}_{8}$, were not successful. Due to synthesis limitations even the unsupported membrane showed only mesoporous nature. A total porosity of $50 \%$ and pore size of $36 \AA$ was calculated from the nitrogen adsorption isotherms. Alumina membranes directly made over the support, gamma alumina layer system were Knudsen diffusing. Separation factors between $\mathrm{C}_{3} \mathrm{H}_{6}$ and $\mathrm{C}_{3} \mathrm{H}_{8}$ remain in the range of the Knudsen value (1.023).

The alumina-silica $\left(\mathrm{Al}_{2} \mathrm{O}_{3}-\mathrm{SiO}_{2}\right)$ system, comprised of an alumina layer over microporous silica, showed activated diffusion for helium. Permeation and $E_{\text {act }}$ values of the $\mathrm{Al}_{2} \mathrm{O}_{3}-\mathrm{SiO}_{2}$ membrane were comparable to that of pure $\mathrm{SiO}_{2}$ membrane (Figs. 4 and 7). Because of the inconsistency in permeation of these membranes, this comparison of absolute flux values is meaningless to some extent. However the results on an $\mathrm{Al}_{2} \mathrm{O}_{3}-\mathrm{SiO}_{2}$ membrane in which the permeation of the underlying $\mathrm{SiO}_{2}$ membrane was first measured showed a similar trend. It can hence be assumed that the coating of the alumina layer did not produce any defects or significant additional resistance. Propylene permeation through this membrane, as evidenced by the low permselectivity of helium (Fig. 7), was very high compared to the pure $\mathrm{SiO}_{2}$ membrane. The increased sorption of $\mathrm{C}_{3} \mathrm{H}_{6}$ over alumina as in Fig. 5a should be the reason. Strong Langmuir adsorption and stable $q_{\mathrm{st}}$ of $\mathrm{C}_{3} \mathrm{H}_{6}$ over alumina are notable. This is evidence of a large number of homogenous adsorption sites on gamma alumina. The steady state surface diffusion will then be comparable to the equilibrium value [21]. Alumina also showed moderate and steady $q_{\mathrm{st}}$ values for propane. The ratios of adsorption capacities and Henry slopes of the two gas molecules showed selectivity for propylene under equilibrium conditions.

The $\mathrm{C}_{3} \mathrm{H}_{6} / \mathrm{C}_{3} \mathrm{H}_{8}$ separation behaviour (Fig. 8) of the $\mathrm{Al}_{2} \mathrm{O}_{3}-\mathrm{SiO}_{2}$ membrane apparently supported this. These membranes have shown reasonably large separation factors $\left(\mathrm{SiO}_{2}\right.$ showed almost no separation) under steady state mixture gas permeation. The reported separation factor of 1.7 at $50^{\circ} \mathrm{C}$ is commendable compared to the Knudsen separation value of 1.023 and that of zeolite MFI membranes (1.25 at $298 \mathrm{~K}$ ) as reported by Vroon et al. [15]. The separation factors are nearly equal to the equilibrium ratio of $\mathrm{C}_{3} \mathrm{H}_{6} / \mathrm{C}_{3} \mathrm{H}_{8}$ adsorption capacities over alumina (in the range 1.5-2 at $50 \mathrm{KPa}$ as in Fig. 5a and Fig. $5 b$ ). Hence the large number of homogenous adsorption sites and surface selectivity of alumina should be the reason for the enhanced separation factor of the $\mathrm{Al}_{2} \mathrm{O}_{3}-\mathrm{SiO}_{2}$ membrane.

Consistency and durability measurements show the problems faced by these membranes. The consistency in permeation through the $\mathrm{Al}_{2} \mathrm{O}_{3}-\mathrm{SiO}_{2}$ membrane is not very high but is a general problem as far as inorganic membranes are concerned. However the separation factor remained nearly the same, for membranes having the same activation energy (the quality of the support can cause problems, as far as non-diffusive flux is concerned) [Ref. [8]a, pp. 197205]. Another difficult thing to control is the formation of the microporous silica layer from the fractal polymers. Condensation reactions happening along 
with drying can lead to variations in porosity of the membrane [9]. Strict control over drying procedures is therefore essential.

Another problem faced by such membranes is the apparent pore blocking by propylene, eventually decreasing the permeation. However frequent heat treatment operations (Fig. 9) can clean the membrane. Hence the problem is not as disastrous as the permanent densification that happens to these sol-gel silica membranes in the presence of water. This densification in the presence of water vapour will be enhanced at higher temperatures. It is realised that the addition of the new layer has not improved the chemical stability of the silica membranes against water vapour.

\section{Conclusions}

1. Microporous silica membranes with commendable permselectivity between helium and propylene can be made by the sol-gel route.

2. The molecular sieve like separating mechanism prevailing in such silica membranes is inadequate to realise good separation values for gas molecules of nearly the same molecular size.

3. Introduction of a sorption selective surface layer with reasonably high adsorption capacity is helpful to increase the separation factor between propylene and propane at low and moderate temperatures.

\section{Acknowledgements}

Our sincere gratitude to Dr. T. Okubo (Department of Chemical System Engineering, University of Tokyo, Japan) for the FESEM analysis and discussions.

\section{References}

[1] R.S.A. de Lange, K. Keizer, J.H.A. Hekkink and A.J. Burggraaf, Formation and characterisation of supported microporous ceramic membranes prepared by sol-gel modification techniques, J. Membrane Sci., 99 (1995) 57-75.

[2] M. Tsapatsis and G. Gavalas, Structure and aging characteris- tics of $\mathrm{H}_{2}$-permselective $\mathrm{SiO}_{2}$-Vycor membranes, J. Membrane Sci., 87 (1994) 281-296.

[3] J.C.S. Wu, H. Sabol, G.W. Smith, D.L. Flowers and P.K.T. Liu, Characterisation of hydrogen-permselective microporous ceramic membranes, J. Membrane Sci., 96 (1994) 227-287.

[4] A.B. Shelekhin, A.G. Dixon and Y.H. Ma, Adsorption, permeation and diffusion of gases in microporous membranes. II. Permeation of gases in microporous glass membranes, J. Membrane Sci., 75 (1992) 233-244.

[5] A. Julbe, C. Guizard, A. Larbot, L. Cot and A. Giroir-Frendler, The sol-gel approach to prepare candidate microporous inorganic membranes for membrane reactors, J. Membrane Sci., 77 (1993) 137-153.

[6] (a) R.J. Uhlhorn, Ceramic Membranes for Gas Separation, Ph.D. Thesis, University of Twente, The Netherlands, 1990; (b) R.J. Uhlhorn, K. Keizer and A.J. Burggraaf, Gas transport and separation with ceramic membranes, J. Membrane Sci., 66 (1992) 271-288.

[7] C.J. Brinker, T.L. Ward, R. Sehgal, N.K. Raman, S.L. Hietala, D.M. Smith, D.-W. Hua and T.J. Headley, Ultramicroporous silica-based supported inorganic membranes, J. Membrane Sci., 77 (1993) 165-179.

[8] (a) R.S.A. de Lange., Microporous Sol-gel Derived Ceramic Membranes for Gas Separation, Ph.D. Thesis, University of Twente, The Netherlands, 1993; (b) R.S.A. de Lange, K. Keizer and A.J. Burggraaf, Characterisation of microporous non-supported membrane top-layers using physisorption techniques, J. Porous Mater., 1 (1995) 139-153.

[9] C.J. Brinker, A.J. Hurd, P.R. Schunk, G.C. Frye and C.S. Ashley, Review of sol-gel thin film formation, J. NonCrystal. Solids, 147/148 (1992) 424-436.

[10] R.H.E. van Doorn, H.J.M. Bouwmeester and A.J. Burggraaf, Phase related oxygen permeation through $\mathrm{Sr}$-doped $\mathrm{LaCoO}_{3-\delta}$, Proc. Electro Chem. Soc. (Chicago), October (1995).

[11] B.N. Nair and K. Keizer, Silica-pillared clay membranes, in preparation.

[12] R.M. Barrer, Porous crystal membranes, J. Chem. Soc., Faraday Trans., 86 (1990) 1123-1130.

[13] J.W. Elferink, B.N. Nair, R.M. de Vos, K. Keizer and H. Verweij, Sol-gel synthesis and characterization of microporous silica membranes. II. Tailor making porosity, J. Colloid Interface Sci., 179 (1996) in press.

[14] J.A. Hampson and L.V.C. Rees, Adsorption of ethane and propane in silicalite-1 and zeolite $\mathrm{NaY}$ : Determination of single components, mixture and partial adsorption data using an isosteric system, J. Chem. Soc, Faraday Trans., 89 (1993) 3169-76.

[15] Z.A.E.P. Vroon, Synthesis and transport studies of thin ceramic supported zeolite (MFI) membranes, Ph.D. Thesis, University of Twente, The Netherlands, 1995.

[16] Z.A.E.P. Vroon, K. Keizer, M.J. Gilde, H. Verweij and A.J. Burggraaf, Transport properties of alkanes through ceramic thin zeolite MFI membranes, J. Membrane Sci., 113 (1996) 293-300.

[17] B.N. Nair, J.W. Elferink, K. Keizer and H. Verweij, Sol-gel synthesis and characterization of microporous silica mem- 
branes. I. SAXS study on the growth of polymeric structures, J. Colloid Interface Sci., 178 (1996) in press.

[18] H. Tamon, S. Kyotani, H. Wada, M. Okazaki and R. Toei, Surface flow phenomenon of adsorbed gases on activated alumina, J. Chem. Eng. Jpn., 14 (1981) 136-141.

[19] R. Ash, R.M. Barrer and P. Sharma, Sorption and flow of carbon dioxide and some hydrocarbons in a microporous carbon membrane, J. Membrane Sci., 1 (1976) 17-32.
[20] B.N. Nair, K. Keizer, H. Verweij and A.J. Burggraaf, Surface selective approach to separation of propylene from propane, Sep. Sci. Technol., (1995) in press.

[21] R.M. Barrer, Surface flow and mixture separation in microporous media, AIChE Symp. Ser., 1 (1965) 112. 